\title{
Concepts in Rehabilitation of Burn Patients
}

\author{
MS RAHMAN ${ }^{\mathrm{a}}$, MA SHAKOOR ${ }^{\mathrm{b}}$
}

\begin{abstract}
Summary:
Burn is not the skin loss only. Functional and psychological outcome must be assessed and treated accordingly. Prevalence of burn injury is very high in Bangladesh though exact statistics is not available. Houses of poor people especially in the slum area, which are made of combustible materials, are vulnerable to set
\end{abstract}

\section{Introduction:}

The human and economic cost of burn injury is enormous. Burn size and age are cardinal determinants of survival. Mortality is highest in the very young and elderly. 1 . Mortality is greater in female than male with comparable injury ${ }^{2}$.

Burn injury is not a new problem. Mankind has struggled with burn injuries since the discovery of fire. Documents as early as Papyrus Erbes in 1600 BC specify burn treatment techniques. ${ }^{3}$. Hippocrates stressed burn wounds with wine or water to avoid suppuration. With the advent of graft technique early closure of burn wound become possible significantly improving survival rates.

Modern burn treatment is the result of a long history of medical and technical advances.

The survival rates of seriously burned patient have increased dramatically, especially in the last three decade. More patients are returning to active lives at home, at work and in the community. The physiatrist is uniquely trained to manage the complex rehabilitation problem of burn injuries and to aid burn patients in returning to a full and productive life.

a. Dr. Md. Shahidur Rahman, Assistance Professor, Department of Physical Medicine and Rehabilitation, Bangabandhu Sheikh Mujib Medical University.

b. Dr. MA Shakoor, Associate Professor, Department of Physical Medicine and Rehabilitation, Bangabandhu Sheikh Mujib Medical University.

Address of correspondence: Dr. Md. Shahidur Rahman, Assistance Professor, Department of Physical medicine and Rehabilitation, Bangabandhu Sheikh Mujib Medical University, Shahbag, Dhaka.

Received: 26 July, 2007

Accepted: 8 August, 2007 off fire. Chemical burns like throwing acids by culprits are common in our country. Hospitals are treating these patients without proper medical and psychological rehabilitation. This article will review the rehabilitation concepts of burn injury and provide some information to those physicians and surgeons who treat burn injury.

(J Bangladesh Coll Phys Surg 2007; 25 : 139-143)

\section{Rehabilitation:}

Once a patient has sustained a burn injury, the rehabilitation phase begins. It continues long after discharge. The goal of rehabilitation is to achieve the optimal level of functioning. The location, depth and distribution of burn injury are important in preventing complications. The extent of injury correlates with survival as well as with time required to return to independent functioning. Age, previous level of independence, premorbid medical condition and other injuries must be considered when assessing the burn patients. ${ }^{4}$,

During acute period goals include promoting wound healing and preventing complications by preserving joint function, strength, endurance and functional abilities. Goals are individualized according to the location and extent of burn injury and previous functional level. Goals are continuously assessed and modified as the patient improves.

\section{Positioning:}

Proper positioning is fundamental to burn rehabilitation. Positioning prevents contracture formation, controls edema and maintains tissues in an elongated state. Because of pain, burn patients assume primarily flexed and adducted position that inadvertently favors contracture development. The positioning program must be individualized in accordance with the sites of injury. Use of splints, pillows and foam wedges, can achieve proper positioning.

\section{Splinting:}

Splints are used to maintain anticontracture position and range of motion in joints at risk for development 
of contracture. Prefabricated or custom splints can be used but proper fitting must be ensured. Splints should be easy to don and doff. The type of splint used is dependent on the area burned, the depth of injury, the patient's functional status and the patient's ability to participate in positioning and exercise program. The functional position of hand is the hand splinted in full interphalangeal extension, 60 to 80 degrees of metacarpophalangeal flexion, thumb abduction and wrist extension. 5,6 .

\section{Exercise in burn rehabilitation}

Exercise is fundamental to maximizing patient function and overall outcome. In prescribing exercise, the extent, depth and location of the injury is considered. The risk of exercise disrupting wound healing requires regular wound inspection. Stretching can also disrupt already tenuous joint. The initial exercise program should focus on preserving ROM and maintain strength. Active forms of exercise are indicated for patients who are alert and able to participate. For critically ill patients, the slow controlled movement of passive ROM exercise is appropriate. Massage is a useful adjunct in burn treatment and rehabilitation.

\section{Ambulation and mobility}

Ambulation and mobility are important elements of a comprehensive rehabilitation program. Early ambulation maintains balance and decreases the risk of deep vein thrombosis. Ambulation should start as soon as possible after admission. Ambulation can be limited by medical status, the depth and extent of lower extremity burns and previous medical conditions such as peripheral vascular disease. Elastic wrap or stockings prevent venous stasis, control edema, and reduces the risk of local trauma and decrease pain induced by dependent position.

\section{Scar Rehabilitation:}

The risk of hypertrophic scar increases with the depth of injury and length of time required for healing. The risk is reported by some authors to be greater in more darkly pigmented areas., ${ }^{7,8}$ Pressure treated scars have better functional and cosmetic outcome. The application of continuous pressure through garments, orthoses and splints is the primary non-surgical modality used to control hypertrophic scarring. The mechanism by which pressure suppresses hypertrophic scarring is unclear, but it has been hypothesized that pressure causes decreased capillary perfusion and decreased tissue oxygenation, resulting in reduced cellular activity and collagen synthesis. ${ }^{9}$. The application of pressure should continue until the scar is mature. Patient education is essential in increasing pressure therapy compliance. Wounds expected to heal in less than three weeks often do not require early surgery and are less likely to develop significant scarring. 10,11. Custom made elastic facemasks and transparent orthoses are available for controlling facial scarring. Silicone and other materials can be added to face masks to achieve better pressure application in regions such as nasolabial folds, ${ }^{12}$. Microstomia correction appliances may be dynamic or static. 13,14 .

The use of pressure garments on grafted burns or burns that take longer than 14 days to heal is considered standard care in most burn care centers, despite the question of its efficacy. ${ }^{15,16 .}$ Topical application of silicone has also been employed to treat burn-related scarring. Much is known about the effect of topical silicone application, but to date, as with pressure garments, no randomized, controlled trials have conclusively demonstrated that such therapy minimizes hypertrophic scarring. ${ }^{17,} 18$. Available tools to modify the progression of hypertrophic scar formation are limited in number and effectiveness. These tools include scar massage, compression garments, topical silicone, steroid injections, and surgery. In some contractures over major joints, serial casting may be useful. ${ }^{15}$

\section{Hands rehabilitation}

Hands are the most common sites of burn injury 19 . Because of the highly specialized functions of the hand, the burned hand requires the care of burn specialists experienced in hand management. Treatment goals include edema control, early wound closure, rapid return of hand function and prevention of hand deformities. After assessing the hand for potential hypertrophic scarring and contracture formation, a well-designed program of exercise, and splinting should be prescribed. Exercise coupled with splint, when indicated can prevent hand deformities and restore hand function. When splints are used, they should maintain the hand in an anticontracture position, which will prevent 
anticipated deformity. This injury requires the hand be splinted in the position of function. Once the wound is covered, passive ROM can be performed judiciously.

\section{Neuromuscular complications:}

Peripheral nerve injuries are common after burns. Neurological involvement includes focal nerve compression, multiple mononeuropathies and generalized polyneuropathies. Focal mononeuropathies commonly occur secondary to positioning, improperly applied splints or bulky dressings ${ }^{17}$. Burn injuries are intrinsically associated with generalized peripheral neuropathy. Approximately $15 \%$ of the patients have the peripheral neuropathy generally occur in patients who have $20 \%$ total burn surface area. The etiology of peripheral neuropathy of burns has not been established, but neurotoxicity from antibiotics and the possibility of a circulating neurotoxin from the burn injury itself have been hypothesized. ${ }^{20,21 .}$

\section{Pediatric burns:}

Mortality rates are higher in infant compared with those in adolescence or adults. Children younger than 1 year are at greater risk for mortality than during subsequent school years. ${ }^{2}$. Children are often unable to cooperate with many aspect of therapy and do not understand long-term goals. Loss of function such as hand dexterity and ROM not only interferes with child's current development level but also can limit future academic and vocational success. Because of the growth, children require more frequent modification of splint and custom fitted pressure garments. It is important to monitor jaw development and dental alignment during the use of facemasks and orthoses to avoid malocclusion 22,23,24. The combination of oxandrolone and exercise offers greater benefits in lean body mass, body weight, and physiologic parameters compared with oxandrolone alone, exercise plus placebo, and placebo alone in severely burned children. ${ }^{25}$

\section{Geriatric burns}

The geriatric patients can be at increased risk for burn injury because of premorbid mobility limitations, visual deficits, impaired sensation and cognitive problems. Knowledge about the patient's functional level prior to the burn injury is important in planning the rehabilitation program. Early mobilization is imperative because the effects of immobility occur more rapidly and more pronounced in elderly persons 26. Well-designed exercise programs can assist geriatric patients in making significant gains in strength and endurance.

\section{Psychological adjustment}

A burn injury can be the most devastating traumatic event a person can experience. Preinjury psychological status is strong predictors of a patient's long-term emotional status after serious burn. ${ }^{27}$ Patients who are previously well adjusted emotionally are likely to adjust the insult. Previous psychological dysfunction is likely to be accentuated by burn trauma. ${ }^{28,29}$. Delirium, adjustment disorders, major depression, and posttraumatic stress disorder are most common psychiatric disorders during recovery from burn injury ${ }^{30}$. Adjustment disorder is the second most frequently encountered disorder. It can persist longer in the presence of chronic conditions, such as disabling medical conditions or financial difficulties as a result of unemployment. ${ }^{31,32}$. Depression and posttraumatic stress disorders are major complication of burn rehabilitation.

\section{Work issues}

Returning to work is an issue of major importance to many burns patients. The presence of hand burns, the type of employment, and age significantly influence return to work. ${ }^{33,34}$. Special problems affecting return to work include skin fragility, heat and cold intolerance, altered sensation and impaired coordination and dexterity. Burn injuries often occur at work and affected individuals may have difficulty returning to the site of their injury. In the case of severe injury approximately 20 to $50 \%$ of the patients require change in occupation.

\section{Outpatient rehabilitation:}

Planning for discharge should begin as early as possible. Education of the patient and the family builds a foundation for all aspect of rehabilitation, including outpatient treatment. At discharge the patient need to be independent in all aspect of care in order to return home. The need for physical and 
occupational therapy does not end at discharge. Ideally the patient should be referred to a therapist with previous experience in treating burn injuries. Therapy program need to focus on ROM, strengthening, endurance, mobility and gait. After discharge the patient faces the task of family and community reintegration. Self-esteem can be significantly altered by changes in the appearances and functional abilities. With post burn injury status; women and girls have lower self-esteem than men and boys who experiences comparable injuries. ${ }^{35}$.

Social studies indicate that the greater the patient's social support from family and friends, the more positive is the body image and higher the sense of self esteem. Symptoms of depression occur less frequently in this group of patients 36,37 . Social support appears to be a key factor in a person's psychological adaptation to a burn injury. ${ }^{37}$.

\section{Conclusion}

Burn is not the skin loss only. Functional and psychological outcome must be assessed and treated accordingly. Rehabilitation should begin at the time of admission. Serious burn injury results in multi system trauma and has implications far beyond skin loss. Collaboration between the physiatrist and burn surgeon managing the patient's acute medical and surgical care should begin immediately on the patient's admission to the burn unit. Integrating the expertise of the burn surgeon and physiatrist will ensure that all aspect of patient care are addressed and the patient will receive burn care services needed to achieve an optimum functional and cosmetic outcome. Success ultimately depends on the combined effort of the patient and the rehabilitation team.

\section{References}

1. Silverstein P, Lack BO: Epidemiology and prevention. In Boswick JA (ed): the art and science of burn care. Rockville. Aspen publisher 1987, p-12- 32.

2. Roi LD, Flora JD Jr, and Wolfe RA: Two new burn severity indices. J Trauma 1983; 23: 1023-1029.

3. Haynes BW Jr; The history of burn care. In Boswick JA (ed): the art and science of burn care. Rockville, Aspen publishers, 1987,p-3-9.

4. Esselman PC, Thombs BD, Magyar-Russell G: Burn rehabilitation: state of the science. Am J Phys Med Rehabil 2006 Apr; 85(4): 383-413[Medline].
5. Helm PA, Kevorkian CG, Lushbaugh M, et al: Burn injury: Rehabilitation management. Archives Phys Med Rehab 1982; 63: 6-16.

6. Levine NS, Buchanan RT: The care of burned upper extremities. Clin Plast Surg 1986; 13: 107-118.

7. Deitch EA, Wheelahan TM, and Rose MP: Hypertrophic burn scars. J Trauma 1983; 23: 895.

8. Rockwell WB, Cohen LK, Ehrlich HP: Keloids and hypertrophic scars: A comprehensive review. Plast Reconstr Surg 1989; 84: 827.

9. Page RE, Rogertson GA Pettigrew NM: Microcirculation in hypertrophic burn scars. Burns Therm Inj 1983; 10: 64-70.

10. Covey MH: Occupational therapy. In Boswick JA (ed): the art and science of burn care. Rockville, Aspen publishers, 1987; pp 285-298.

11. Robson MC, Smith DJ: Reconstruction of burned face, neck and scalp. In Boswick JA (ed): the art and science of burn care. Rockville, Aspen publishers, 1987; pp 375-376.

12. Ward RS, Reddy R, and Lundy $\mathrm{C}$ et al: technique for control of hypertrophic scars in the central region of the face. J burns care rehabil 1991; 12: 263.

13. Conine TA, Carlow DL and Stevenson MP: Dynamic orthoses for the management of microstomia. J Rehabil Res Dev, 1987; 24: 43-48.

14. Conine TA, Carlow DL and Stevenson MP: Static orthoses for the management of microstomia. J Rehabil Res Dev, 1987; 24: 35-42.

15. Faucher Lee D, Trauma and Thermal Injury, Rehabilitation of the Burn Patient, ACS Surgery Online, Dale DC; Federman DD, Eds. Web MD Inc., New York, 2000. http//www.medscape.com.

16. Carr-Collins JA: Pressure techniques for the prevention of hypertrophic scar. Clin Plast Surg 1992 Jul; 19(3): 73343[Medline].

17. Sheridan RL, Burn Rehabilitation, Scar Management; www.emedicine.com,Inc. Updated January 26, 2007.

18. Ahn ST, Monafo WW, Mustoe TA: Topical silicone gel for the prevention and treatment of hypertrophic scar. Arch Surg 1991 Apr; 126(4): 499-504[Medline].

19. Salisbery RE, Dingeldein GP: The burned hand and upper extremity. In green DP (ed). Operative hand surgery, edn. 2, vol 2 churchill Livingstone 1988, p- 1523.

20. Helm PA, PandianG, Heck E; Neuromuscular problems in burn patients: causes and prevention. Arch Phys Med Rehabil 1985; 66: 451-453.

21. Handerson B, Koepke GH, Feller I; Peripheral polyneuropathy among patients with burns. Arch Phys Med Rehabil 1971, 52: 149-152.

22. Sepulcre C, Moati F: biochemical and pharmacological properties of a neurotoxic protein isolated from blood serum of heavily burned patients. J pathl. 1979, 127: 137-145. 
23. Fader P: Preserving function and minimizing deformities: In Carvajal HF, Parks DS (ed) s. Burns in children. Chicago, Year Book Medical Publishers 1988, p 335.

24. Leung KS: Complications of pressure therapy for post burn hypertrophic scars. Burns 1984; 10: 434-438.

25. Laurie Barclay, Oxandrolone Plus Exercise Increases Muscle Mass, Strength in Children With Severe Burns. Mediscape medical news, Jan 16, 2007. www.medscape.com

26. Bortz WM II: Disuse and aging. JAMA 1982; 248: 12031208 .

27. Questad KA, Patterson R, Baltwood MD, et al: relating mental health and physical function at discharge to rehabilitation status at 3-month post burn. J burns care rehabil 1988; 9: 87-89.

28. Sheridan RL, Hinson MI, Liang MH: Long-term outcome of children surviving massive burns. JAMA 2000 Jan 5; 283(1): 69-73[Medline]

29. Steiner H, Clark WJ Jr. Psychiatric complications of burned adults: A classification. J Trauma. 1977; 17: 134-143.

30. Watkins PN, Cook EL, May SR et al: The role of psychiatrist in the team treatment of the adult patients with burns. J burn care rehabil 1992; 13: 19-27.

31. Adler R: Burns are different: The child psychiatrist in the pediatric burn ward. J burn care rehabil 1992; 13: 28-32.
32. 24. Bowden ML, Thomson PD, Prasad JK: Factors influences return to employment after a burn injury. Arch Phys Med Rehabil 1989; 70: 772-774.

33. Cheng S: Changes in occupational role performance after a severe burn. A retrospective study. Am J Occup, Ther 1989; 43: $17-20$.

34. Orr DA, ReznikoffM, and Smith GM: Body image, Self esteem and depression in burn injured adolescences and young adults. J burns care rehabil 1989; 10: 451461.

35. Steiner H, Clark WR Jr: Psychiatric complications of burned adults: a classification. J Trauma 1977 Feb; 17(2): 13443 [Medline].

36. Bowden ML, Feller I, Tholen D, Self esteem in severely burned patients. Arch Phys Med Rehabil 1980; 61: 449-452.

37. Knudson-Cooper M: what are the research priorities in the behavioral areas for burned patients? J Trauma 1984; 24 (suppl 9): S 197- S201.

38. Sheridan RL: Burn care: results of technical and organizational progress. JAMA 2003 Aug 13; 290(6): 719-22[Medline].

39. Berger M, Wilson S: Burns rehabilitation is more than skin deep. BMJ 2004 Sep 4; 329(7465): 573-4[Medline].

40. Pessina MA, Ellis SM: Burn management. Rehabilitation. Nurs Clin North Am 1997 Jun; 32(2): 365-74[Medline]. 